\title{
Trade networks and shock transmission capacity: a new taxonomy of Italian industries
}

\author{
Stefano Costa $^{1} \cdot$ Federico Sallusti $^{1} \cdot$ Claudio Vicarelli $^{1}{ }^{1}$
}

Received: 7 May 2021 / Revised: 12 January 2022 / Accepted: 13 January 2022 /

Published online: 29 January 2022

(c) The Author(s) under exclusive licence to Associazione Amici di Economia e Politica Industriale 2022

\begin{abstract}
Applying the social network analysis to domestic and international input-output tables, we position the Italian sectors within their trade networks to analyze their ability to transmit economic shocks within the economic system. In this context, we propose a new taxonomy that classifies sectors in terms of the extent to, and the speed at, which they tend to spread domestic and foreign impulses throughout the Italian economic system. Our results show a mismatch between the industries which have a central position within international trade network and industries which play a central role for the domestic propagation of shocks. In this vein, the capacity of transmitting stimuli from abroad is limited, weakening the possibility to benefit from positive shocks, even though it could partially provide a shelter from negative one in the international business cycle.
\end{abstract}

Keywords Input/output tables $\cdot$ Network analysis $\cdot$ Shocks transmission

JEL Classification D57 · E30 · F14

\section{Introduction}

Trade networks represent a relevant vehicle for the transmission of economic shocks. The structure of inter-sectoral relationships contributes to determine how factors such as productivity dynamics, technological progress, increase or decrease in demand can affect the business system through trade relationships along supplychains. Furthermore, transmission also operates at an international level, through the links connecting a country's exporting (importing) sectors to foreign importing (exporting) industries. In the last decades, these factors have increased their importance, as the international interconnectedness across sectors has risen and the

Claudio Vicarelli

cvicarelli@istat.it

1 Istat, Istituto Nazionale di Statistica, Via Cesare Balbo 16, Rome, Italy 
relevance of international trade has increased with growing participation in global value chains (GVCs).

However, the extent and speed of transmission can be heterogeneous between and within countries: industries and firms can be more or less central in trade networks. In this context, a mismatch may emerge between sectors that are central for the international transmission of shocks and those that are central for their domestic propagation. In other words, a sector could be strongly connected with other foreign sectors, so representing a potential transmission channel for exogenous shocks; however, if it is not central within the domestic trade network, its ability to transmit shocks into the domestic economy would be weak. Conversely, a sector with little or no foreign trade links could be central within the domestic trade network; in such a case, a shock originating in that sector could spread widely and rapidly across the domestic economy but with little impact on foreign markets.

This intuition is at the origin of the main contribution of this paper. We propose a new taxonomy of Italian business sectors which is based on the speed and the extent of their capacity of transmitting impulses across the domestic system. In doing so, we account for the existence of the aforementioned mismatch between sectors that are central for the international transmission of shocks and those that are central for their propagation within the Italian economy. In particular, our aim is to analyze how shocks spread across the Italian business system through domestic inter-sectoral relationships. ${ }^{1}$ In this context, we analyze the positioning of industries within both the international and the domestic trade, in order to verify possible mismatches in the structure of the two networks.

For Italy, this analysis is relevant for at least three reasons. First, the business system is extremely fragmented: in 2018, Italian firms with less than 10 workers accounted for $95 \%$ of total enterprises, $44 \%$ of total employment and nearly $30 \%$ of total value added (99.9\%, 79\% and 69\% for SMEs, respectively). Second, according to Eurostat data, in the same year the top 50 Italian exporters accounted for about $25 \%$ of total export, a value comparable to that of top 5 exporters in France and Germany. Third, a substantial part of Italy's manufacturing activities are deeply involved in GVCs, such as textiles, leather and footwear, metal products, chemicals, pharmaceutics, machinery, motor vehicles, other transport equipment (which, according to Istat data, in 2018, accounted together for nearly $47 \%$ of total exports). All these sources of heterogeneity may generate potential mismatches between domestic and international channels of shock transmission.

The rest of this paper is organized as follows. Section 2 briefly recalls the literature of interest. Section 3 summarizes the tools and concepts of Network analysis we use along the work. Section 4, taking a country-based perspective, analyzes the position of the Italian economy within the international trade network. Section 5, taking a sector-level perspective, positions Italian industries both in international and

\footnotetext{
${ }^{1}$ This framework has recently been used for studying the sensitivity of Italian economy to the business cycle fluctuations of Germany, US and China (Istat, 2019); to measure the economic impact of recent exogenous shocks, such as those related to the US-China trade war (Istat, 2020a) or the spread of the Covid-19 pandemic (Istat, 2020b).
} 
domestic networks. Furthermore, it proposes a new taxonomy of sectors according to the speed at, and the extent to, which they propagate shocks within the Italian economic system. Section 6 concludes.

\section{Relevant literature}

This paper empirically contributes to the extensive literature that applies social network analysis (SNA) to international input-output (IO) tables in order to study the propagation of economic shocks through trade networks.

Theoretical and empirical literature has deeply analyzed how shocks amplify and propagate through the economies causing sizeable fluctuations. Generally, the issue has been approached using a macroeconomic perspective: among others, shocks can originate from, and be transmitted through, real effects (investments, capital accumulation, productivity, trade, technology) or financial channels (capital controls, liquidity, banking system, credit market friction), as well as changes in monetary policy. $^{2}$

More recently, the empirical literature has showed that business cycles may originate from micro disturbances (Acemoglu et al., 2012; Baqaee \& Farhi, 2019; Carvalho \& Gabaix, 2013; Costa et al., 2021; di Giovanni \& Levchenko, 2012; di Giovanni et al., 2014, 2018; Gabaix, 2011). In particular, this would occur in two cases: (a) when firms are large enough to significantly affect the dynamics of a country's GDP, value added or exports (the granular hypothesis by Gabaix, 2011); (b) when the linkages among industries are such as to allow for possible shocks occurring in a single industry to spread to the rest of the business system (Acemoglu et al., 2012; Carvalho \& Gabaix, 2013). These issues are especially relevant where concentration of exports or foreign direct investments among the largest players is higher than the concentration of output or employment (Barba Navaretti et al., 2011; Mayer \& Ottaviano, 2007).

Taking a sector-level perspective, several works used IO tables to analyze the role of inter-sectoral relationships in the transmission of international shocks within economic systems. The importance of international shock transmission has gradually grown together with the increasing participation of firms and countries in GVCs. Moreover, trade relationships between industries of different countries can lead to the transmission of national shocks across borders, contributing to the co-movements of international business cycles. Long and Plosser (1983) pioneered the study of sectoral

\footnotetext{
2 Theoretical and empirical literature has widely analyzed these issues for decades. Here we can just limit to recall some of the main seminal works. Stock and Watson (1999) verified the empirical relationship between US aggregate business cycle and various macroeconomic variables, such as production, interest rates, prices, productivity, sectoral employment, investment, income, and consumption. Kydland and Prescott (1982) pointed out the investment and capital accumulation responses in real business cycle models; Frankel and Rose (1998) investigated the relationship between international trade patterns and international business cycle correlations; Bernanke et al. (1999) highlighted the role of credit market frictions facing firms, households, or banks; Friedman and Schwartz (2008) analyzed the consequences of monetary policy.
} 
co-movements using a network model, sowing the seeds of a rich literature that focused on aggregate volatility generated by idiosyncratic shocks. These latter are found to have large effects when there are strong relationships between firms and/or industries (Acemoglu et al., 2015, 2000; Conley \& Dupor, 2003; Dupor, 1999; Foerster et al., 2011; Horvath, 1998; Jones, 2012). Acemoglu et al. (2016a) focused on the propagation of various types of shocks to the US economy (imports from China, changes in Federal government spending, total factor productivity shocks, knowledge/productivity stimuli resulting from changes in patents from foreign sectors) jointly using geographical networks and IO relationships. Shea (2002) analyses the relevance of relationships between sectors in the co-movements between US industries. Alatriste Contreras and Fagiolo (2014) study different models of shocks diffusion among advanced economies; they find that the extent and heterogeneity of the impacts within national economies depend on whether or not the shocks modify the structure of sectoral interdependencies and their productive capacity.

IO tables represent therefore a long-standing tool to understand the topology of interindustry interdependencies and their repercussions on advanced economies. Recently, multi-regional IO databases have been produced, where the most adopted among them is world input-output database (WIOD), boosting the study of inter-country, inter-sectoral interdependencies (see Xing et al., 2016 for a survey).

Furthermore, over the last two decades international linkages has been analyzed also using SNA, an approach previously applied to different disciplines including physics, health science and sociology. In economics, this approach has been used, among others, to explain the evolution of trade of goods and services (De Benedictis et al., 2014; Fagiolo et al., 2010), financial flows across countries (Minoiu \& Reyes, 2013), innovation diffusion among firms, or the adoption of new products (Acemoglu et al., 2016b).

Several works applied SNA tools to different types of international IO tables (WIOD, ICIO etc.) to understand the structural characteristics of GVCs. Cerina et al. (2015) analyze the global, regional, and local network properties of the world IO network, also documenting its evolution over time. Acemoglu et al. (2012) consider the characterization of different sectors to explain aggregate economic fluctuations. Tsekeris (2017) analyzes country, sector and country-sector value chain networks to identify the main drivers of structural changes during the period 1995-2011. Criscuolo and Timmis (2018) use SNA to identify the position within the GVCs of central and peripheral European economies and sectors; Xiao et al (2017) apply various SNA tools to improve the understanding of equipment of manufacturing-related GVCs as well as the interdependency of countries involved in GVCs. Finally, Giammetti et al. (2020) identify key industries in the structure of the UK-EU trade relationships, providing different rankings of the most "systemically important" industries involved in the Brexit process.

\section{Methodology}

In this paper, we use several indicators drawn from SNA. In this context, a brief recall of their definitions and characteristics appears necessary to better understand our results. 
We visualize networks using two types of sociograms (or graphs). In the first one nodes (countries and sectors in our case) are positioned based on distance (expressed in terms of trade relationships) and repulsion (which tends to isolate nodes with few or no ties). This type of sociogram depicts the structure of trade relationships shaping clusters of connected nodes. In the second visualization nodes are positioned on the basis of their centrality in the trade network. In this case, the sociogram shows the structure of the central and peripheral relationships. ${ }^{3}$

However, when the number of links is very high, to focus on the relevant relationships some restrictions are usually applied, such as ruling out, for every node, all its "marginal" inflows or outflows (e.g., flows below the average value of transactions). Another way to select the relationships involving the relevant nodes is to consider, for each node, its "ego-network". This latter is a "sub-network" consisting of the given node ("ego") and the nodes to whom ego is directly connected to (the "neighbors"), plus a given number $(\mathrm{N})$ of ties, if there are any, among the alters (N-neighborhood).

Beside visualization tools, SNA also provides several indicators to assess the importance of a node, capturing different aspects of its positioning (Borgatti, 2005). Among the most used ones, centrality index gives a first measure of how each node is positioned with respect to the overall network, considering its relationships with all the nodes inside and outside the cluster to which it belongs.

In this work, we make use of two types of centrality index: the degree centrality and the eigenvector centrality. ${ }^{4}$ The former is the simplest quantitative representation of the positioning of a node in a network. In its basic form, the centrality is measured by the number of connections of the given node. When arcs are weighted (e.g. by the value of a transaction), the measure becomes the strength centrality (Jackson, 2010). Moreover, when comparing two different networks (e.g. with different numbers of nodes and arcs), a node's degree centrality (strength-centrality) is usually normalized by the number of all its possible neighbors $(N-1)$, so that the normalized degree centrality ranges from 0 to 1 (the closer to 1 the indicator is, the more the node is directly connected to the rest of the network). In a directed network, there will be two measures of degree (or strength) centrality: in-degree (or in-strength) centrality, measuring the number of arcs pointing to a node, and outdegree (or out-strength) centrality, measuring the number of arcs pointing away from a node.

The degree centrality and the strength centrality are essentially local centrality measures. They take into consideration only a node's direct links (i.e. its nearest neighborhoods), regardless of its position in the network. However, the position of

\footnotetext{
3 General overviews of the formal descriptions of graphs and networks can be found in Wasserman and Faust (1994) and Jackson (2010).

${ }^{4}$ Centrality measures can be classified into four main groups (Jackson, 2010): (a) degree centrality, that measures how a node is connected to others; (b) closeness centrality, showing how easily a node can be reached by other nodes; (c) betweenness centrality, describing how important a node is in terms of connecting other nodes; (d) eigenvector centrality (or the Bonacich centrality), associating a node's centrality to its neighbors' characteristics, directly referring to how important, central, influential or tightly clustered the neighbors are.
} 
the node also depends on the position of all other nodes, the effect of which can be accounted for by moving from local to global centrality measures.

A global measure is the eigenvector centrality. The basic idea is that a node is relevant (central) if it is linked to other important (central) nodes. It follows that a node's eigenvector centrality is determined by the eigenvector centrality of its neighbors. Bonacich's (1972) eigenvector centrality defines the centrality of a given node as the sum of the eigenvector centralities of its neighbors.

\section{Italy in the structure of international trade network}

In the last decades, the removal of trade barriers has made the world economy progressively more integrated, involving both advanced and emerging countries. It was strongly fueled by the progress achieved in the numerous trade rounds at the GATT and the WTO, the signing of free trade agreements and currency unions, the increasing importance of FDIs (Krugman et al., 1995), the fragmentation of global production, which also allowed emerging countries to participate in the worldwide process of creation of value (Baldwin, 2013). Consequently, shock transmission through trade channels are today stronger and more pervasive than they used to be a few decades ago, and the structure of international trade networks plays a crucial role in determining the extent and speed of shocks transmission.

To highlight the main structural characteristics of these networks and study the position of the Italian business system, in this paper we apply SNA to the WIOD tables that provides information on trade relationships among 50 industries of 40 countries. Moreover, in order to take into account also the structure of Italy's domestic trade relationships, we use a "corrected" version of the WIOD tables: for their sub-matrix regarding inter-sectoral trade within the Italian economy, we use the most recent Istat IO tables, referred to $2017 .^{5}$

Figure 1 depicts the structure of world trade relationships. ${ }^{6}$ Circumference of the nodes represents the weight of countries in terms of value added, while the thickness of the arcs represents the magnitude of transactions. Finally, colors represent proximity clusters, identified by the faction algorithm, which groups countries based on the intensity of their bilateral relationships. ${ }^{7}$

Four major trade areas are identified: Central-Eastern Europe, Central-Western Europe, Scandinavian countries and Rest of the World. As for connections among European countries, an important role is played by trade relationships between Italy, Germany and France, which represent a "bridge" between the groups of CentralEastern and Central-Western Europe. Linkages with non-European countries involve

\footnotetext{
${ }_{5}$ For this reason, in this paper Figs. 1, 2, 3, using only WIOD data, refer to 2014; Figs. 5 and 6 and Tables 1, 2 and 3, using only Italian IO data, are related to 2017.

6 See Timmer et al. (2015). The latest edition of WIOD refers to 2014. Graphical representations, as well as indicators shown in the rest of the analysis, are drawn using the UCINET software (Borgatti et al., 2002).

7 In order to graphically represent the network of international trade and derive centrality indicator, the original matrix of trade flows has been processed in order to maintain only "relevant" links. In particular, the matrix has been normalized so as to assign each cell its relative weight in terms of both inward and
} 


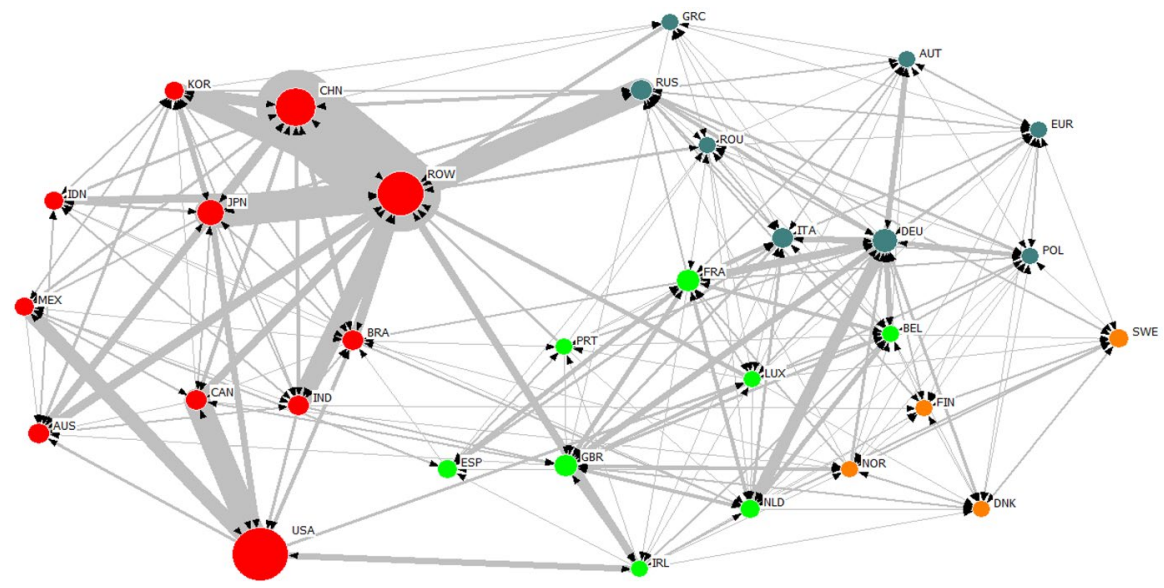

Note: colours indicate clusters, grouping countries based on the intensity of their bilateral relationships. Circumference of the nodes is proportional to country's value added; the thickness of the arcs is proportional to the magnitude of bilateral transactions.

Fig. 1 International trade relationships and cluster of countries, 2014. Colours indicate clusters, grouping countries based on the intensity of their bilateral relationships. Circumference of the nodes is proportional to country's value added; the thickness of the arcs is proportional to the magnitude of bilateral transactions. Source: Authors' calculations on WIOD data

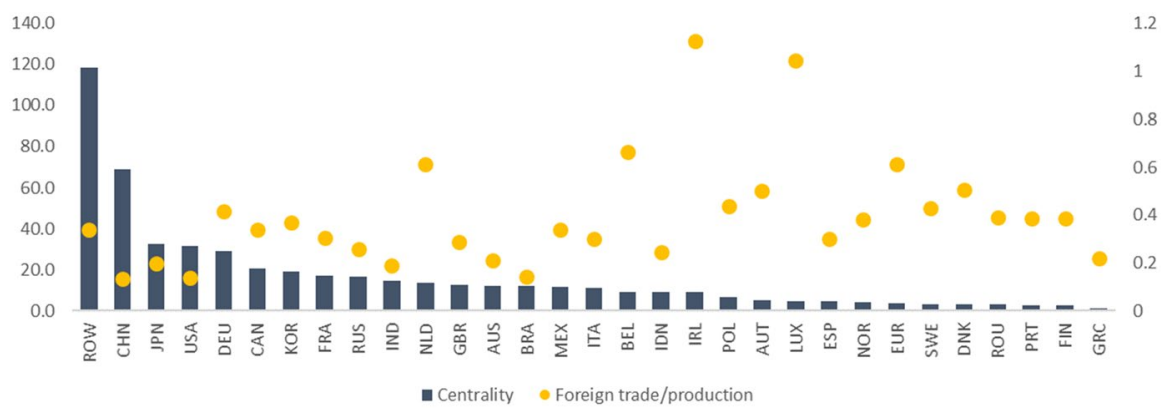

Note: countries' strength centrality is calculated as the sum of their in-strength and out-strength centrality values.

Fig. 2 Strength-centrality and trade openness, 2014. Countries' strength centrality is calculated as the sum of their in-strength and out-strength centrality values. Source: Authors' calculations on WIOD data

essentially Russia and UK (with the Rest of the World) and Ireland and Luxembourg (with the US).

\section{Footnote 7 (continued)}

outward flows. Moreover, trade links representing a proportion less than 3\% of total selling or purchasing for each country in the bilateral relationship have been zeroed. This threshold has been selected applying an elbow rule. Faction algorithm allows to cluster (to split in factions) the nodes of a network by severing loose relationships among groups of strongly connected nodes in order to separate them in sub-groups. See also Borgatti et al. (2018). 


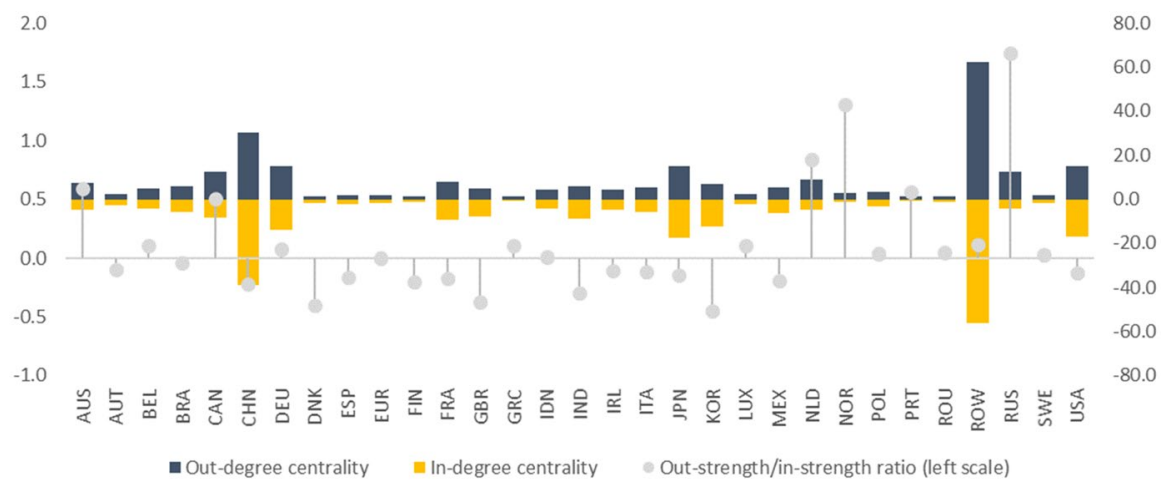

Fig. 3 In-strength and out-strength centrality, 2014. Source: Authors' calculations on WIOD data

In this context, considering strength-centrality ${ }^{8}$ permits to study more in depth the role of each country within the trade network. In this respect, Fig. 2 shows that China, the US and Japan are the most interconnected countries (also taking into account trade openness, measured by the ratio between trade and output values). Among European countries, Germany, UK, France and the Netherlands show a higher strength centrality than Italy, which in turn ranks intermediate. Furthermore, a country's strength centrality in the network of trade relationships is not directly linked to its export propensity; on the contrary, most central countries tend to have a lower trade openness with respect to peripheral ones.

To distinguish the role of exports and imports, the overall strength centrality of each country is broken down in out-strength and in-strength centrality (according to the direction of trade): a higher (lower) out-strength than in-strength centrality signals the tendency of the country's economic system to establish denser trade networks in the upstream (downstream) portions of the GVCs.

Figure 3 shows, for each country, the in-strength and out-strength centrality and their differentials (positive values indicates a higher out-degree). Some countries tend to position themselves in the upstream phase of production processes: Russia, Norway and Canada (which play a significant role in energy supply), Germany, (which confirms its leading role within GVCs, see World Bank et al., 2017), and the Netherlands, Luxembourg and Portugal (which are able to attract FDIs, mainly involving trade in services).

Other advanced countries tend to position themselves in the downstream phases of GVCs, albeit with a very different degree of centrality: highest for China, Japan and the US, smaller for France, much lower for UK and Italy (Italian in- and

\footnotetext{
${ }^{8}$ As mentioned in Sect. 2, the measures of strength centrality used in this work, like those in Figs. 2 and 3 , are weighted by the value of the trade relationships. Therefore, nodes with the same number of relevant links can have different levels of degree centrality (in and out) if the economic relevance of the links is different.
} 
out-strength are about one third than the US ones and about six times lower than the Chinese ones).

In other terms, the Italian business system is characterized by a relatively high degree of participation in the international trade network, but this takes place especially within the sub-networks of European countries, in particular through the relationships with Germany and France. This implies that international shocks spread to the Italian business system mainly through connections with the other large European economies, which also tend to intermediate the impulses from the rest of the world.

\section{The sectoral structure of domestic trade and shocks transmission}

The positioning of Italy within the international trade network represents the synthesis of how the business sectors trade with foreign countries. In this respect, Fig. 4 shows how Italian industries are linked to each other and to foreign countries. Grey arcs indicate the domestic inter-sectoral network; orange arcs depict both the international trade network of 60 Italian industries and bilateral trade between foreign countries. The positioning of nodes is obtained through a gravitational algorithm. ${ }^{9}$ In this context, the aim of the graph is stressing the most relevant Italian sectorsforeign countries proximities. ${ }^{10}$

On the right-hand side of the graph, grey relationships, those internal to the Italian business system, are concentrated. Sectors involved are almost exclusively services, which are generally less connected with foreign countries (Istat, 2019). This is particularly evident for many non-market services (public administration, healthcare, education, culture, codes from ITA52 onward), which are confined in the right far end of the graph. Interestingly, the gravitational algorithm also locates in this part of the network three countries-UK, Luxembourg and Ireland-where tertiary activities, particularly insurance and financial intermediaries, are more developed. Not surprisingly, then, the Italian financial intermediaries and Insurance (ITA39, ITA40, ITA41) are positioned next to these three countries. Finally, Rest of the world (ROW) is positioned close to Italian logistic and transport services.

In the left-hand part of the figure, some relevant industries are concentrated, which are strongly interconnected with foreign countries. They appear closer to a number of foreign countries than to the rest of the Italian activities, mainly services. In particular, they form two clusters: the first one, in the lower-left side of the network, includes metal products (ITA14), electrical equipment (ITA16),

\footnotetext{
${ }^{9}$ In this case, each node is placed in the network according to the intensity of its relationships, represented by the monetary value of the transactions. In particular, all the links between Italian sectors and foreign countries are displayed, while the relationships among Italian sectors are zeroed when their share on total selling and purchasing values is below $3 \%$.

${ }^{10}$ As in Fig. 1, the position of sectors and countries is determined by the location of potential clusters of nodes (in terms of relative proximity/distance) rather than by the centrality of the nodes. For example, in Figs. 2 and 3 Rest of the world has by far the highest degree of centrality, while in the network reported in Fig. 4 it seems to be peripheral.
} 


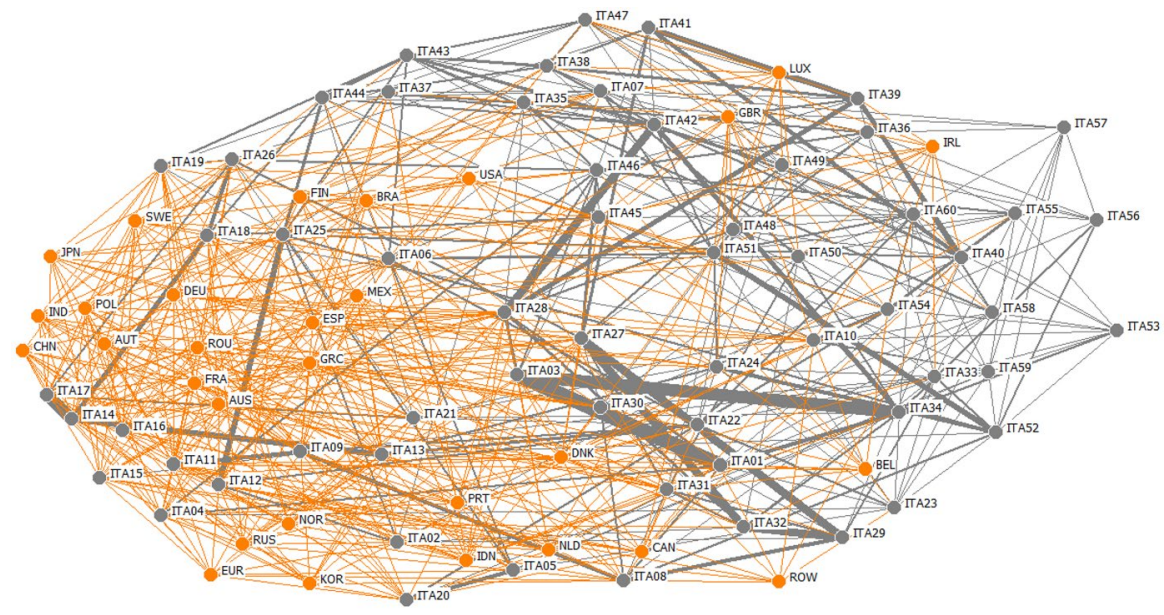

\begin{tabular}{|c|c|c|c|c|c|c|c|c|}
\hline |TAOM1 Agricolture & |Tha11 Rubber and plassics & ITR21 Maintenance and repair & ITR31 Airtransport & 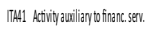 & 1T551 Other business services & AlNS Australia & FiN Finland & MEX Mexico \\
\hline ITMan Mining and quarring & ITA12 Non metal lic mineral prod. & ITR22 Energy (exetricity,gas, steam, airc & ciTR32 Warethosing and supportact. & ITA2 Real estateservices & ITT52 Public administration & AUT Austria & FPA France & NDD The Netherlands \\
\hline ITAN3 Food, bereerges and tob. & ITA13 Basic metals & ITR23 Water supply & ITR33 Postal and currerer activtes & ITMA3 legal activites & ITA53 Edvation & BEl Belgium & GPR UK & NOR Norway \\
\hline ITAM Textile, werring app. and leather & ITAL4 Metal products & ITR24 Wastemanagenenent & ITR33 Accomoddition and food serv. & ITA44 Acchit.and engenering act. & ITF54 Humanhealth activites & BRA Brazil & GRC Greare & POL Poland \\
\hline ITANOS Wood producs & ITA15 Electronics (Comp, elect and opt prod.) & ITR25 Constuction & TTM35 Publisting activitites & ITASS Scient. resererch and derlopom. & ITAS5 Social care & CAN Canada & IDN Indonesia & PRT Portugal \\
\hline ITANG Paper products & ITA16 Electical equipment & IT226 Sale of motor vaticles & ITR36 Programming and broadc. act. & ITAG Alvetising & ITA56 Culture & CHN Ching & IND India & ROU Romania \\
\hline TTAD7 Prinhing & ITA17 Machinery & ITR27 Wholesaletrade & ITR37 Telecommurications & ITA77 Other professional serices & ITA57 Entrettimment and recereation & DeU Germary & IRLi lealan & ROW Restof the World \\
\hline ITAMB Coke and refined pertoleum products & ITA18 Motor vehicles & ITR28 Retal trade & ITr38 Informetics & ITAB Rertand lessing & 1TASB Trade Lhions, political parties & DWK Denmark & PNI lapan & RUS Russia \\
\hline TTMPS Chenicals & ITA19 Othe transport equipnents & ITR29 landtansport & ITR39 Finanoial services & ITAM9 Emplopmentactivites & ITF59 Computess repair & ESP Spain & KOR South Korea & SWE Swiveden \\
\hline ITAli phammeceutios & ITH20 Other manufucturing & TTR30 Water transport & ITAAO Insurance activities & ITF5O Travel agracies & TTa60 Other personal sevices & ER Oher EV & UXX Lxemburg & USA United States \\
\hline
\end{tabular}

Note: In this graph, 60 Italian sectors are represented, following the classification of Italian IO table. Grey arcs indicate domestic transactions, orange ones refer to trade between Italian sectors and foreign countries, as well as among foreign countries. The positioning of the nodes is obtained through a gravitational algorithm that places sectors and countries based on the existence and intensity of their relationships (the distance is represented by the inverse of the value of trade and repulsion).

Fig. 4 Graph of domestic and foreign trade relationships of Italian production sectors, 2014 (orange arcs) and 2017 (grey arcs). In this graph, 60 Italian sectors are represented, following the classification of Italian IO table. Grey arcs indicate domestic transactions, orange ones refer to trade between Italian sectors and foreign countries, as well as among foreign countries. The positioning of the nodes is obtained through a gravitational algorithm that places sectors and countries based on the existence and intensity of their relationships (the distance is represented by the inverse of the value of trade and repulsion). Source: Authors' calculations on Istat and WIOD data

electronics (ITA15), machinery (ITA17) and textiles/wearing apparel/leather (ITA04). The second cluster, in the upper-left side, includes motor vehicles (ITA18), other transport equipment (ITA19), sales of motor vehicle (ITA26) and construction (ITA25). Finally, halfway between the two clusters, there is a group of European countries that are particularly relevant for trade relationships of these industries: Germany, France and some countries of the Central and Eastern Europe (Romania, Poland, Austria).

International shock transmission, however, is a phenomenon partly distinct from impulse propagation within an economic system. The former depends, as we have seen, on the structure of relationships between industries in different countries; the latter relates to the trade network linking sectors within a given country. It is therefore possible that a mismatch emerges between industries that 


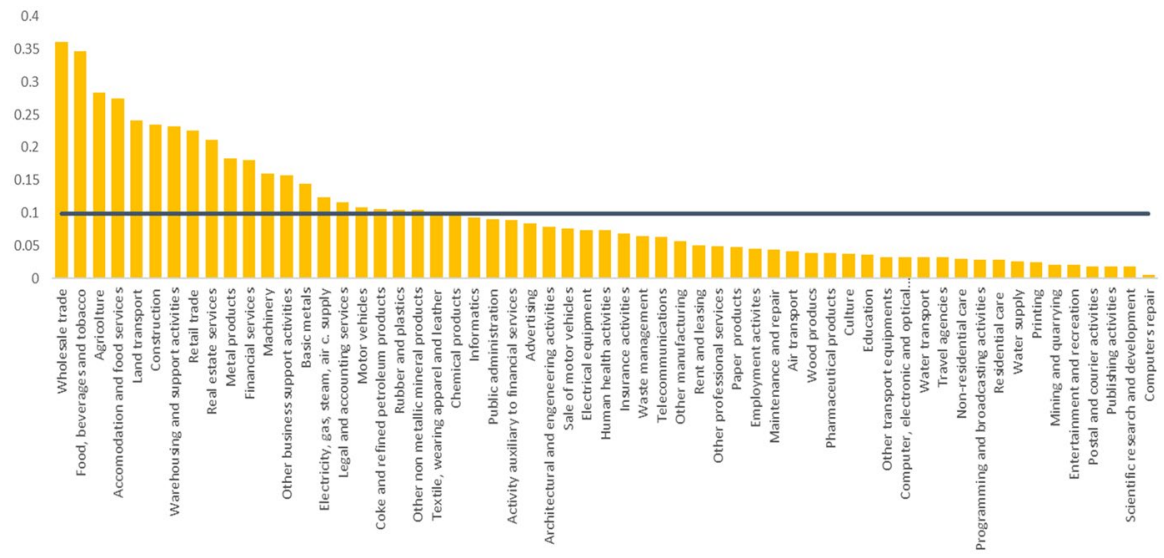

Fig. 5 Eigenvector centrality, 2017. Source: Authors' calculations on Istat data

are central for the international transmission of shocks, and those that are central for its domestic propagation. This possibility will help explain how quickly the shock moves from one country to another and how pervasive their effects on the "receiving" system are likely to be.

Consequently, in order to understand how the Italian economic system absorbs exogenous shocks, we need to evaluate the domestic structure of the sectors trade network. Here, in particular, we investigate whether a specific industry is linked to sectors playing a central or peripheral role in terms of connectivity. For this reason, we look at the eigenvector centrality, obtaining a measure of the importance of sectors in shock transmission: higher values indicate the presence of large and cohesive (high-density) sub-networks.

According to the eigenvector centrality ranking (Fig. 5), only one third of sectors lay above the average, with wholesale trade, food, beverages and tobacco and agriculture at the top. Among services sectors, accommodation and food services, land transport, warehousing and support activities show also values above the average, while in manufacturing, besides food, only metal products and machinery show a significant centrality. Other important manufacturing sectors, such as textiles, wearing apparel and leathers, and motor vehicles, are characterized by a less central position within the economic system. Among the peripheral sectors, some knowledge and technology-intensive activities, such as pharmaceuticals, computers and electronics, scientific research and development, stand out.

However, to properly outline the role of sectors within the Italian economy, at least two other elements need to be accounted for: the size (number of sectors included) and density (share of active relationships on potential ones) of their egonetwork. ${ }^{11}$ In particular, size represents an indicator of the extent of shock transmission, while density proxies the speed of shock propagation.

$\overline{11}$ For each sector, we consider ego-networks taking into account 2 neighbors. 
Considering together the size and density of ego-networks, we propose a new taxonomy of industries according to their capacity of transmitting impulses to the rest of the business system. This provides an ultimate map of how the Italian intersectoral relationships react to a shock. In particular, depending on whether the size and the density of a sector's ego-network are higher or lower than the average, a four-group taxonomy of activities can be defined:

- Weak transmission sectors: activities with ego-networks characterized by limited scale (size below the average) and low density (density below the average).

- Hierarchical transmission sectors: activities with ego-networks that are large (size above the average) but not dense (density below the average). We call such activities "hierarchical transmission" because, beside these characteristics, they also largely present a high degree of intermediation capacity within their own ego-networks (betweenness centrality above average). ${ }^{12}$

- Selective transmission sectors: activities with ego-networks that are small (size below the average) but dense (density above the average). Differently from the previous group, these firms are mostly characterized by a low intermediation capacity within their own ego-networks (betweenness centrality below average).

- Widespread transmission sectors: activities with ego-networks that are wide (size above the average) and dense (density above the average).

In the case of widespread transmission sectors, impulse propagation tends to reach a large number of sectors and it is strengthened by the strong connection among industries (as a reflection of the density of their ego-networks). These are therefore sectors able to transmit impulses to the rest of the business system in an extensive and rapid way. Selective transmission sectors tend to propagate stimuli fast but on a limited scale, while a slow but extensive transmission characterizes hierarchical transmission sectors. Finally, weak transmission sectors propagate shocks slowly and to a limited extent, due to both the limited number of potentially involved sectors and the low density of relationships within the ego-network.

Table 1 shows the distribution of economic activities within these four groups. In particular, looking at the industries with the highest centrality in the domestic network (as highlighted in Fig. 5), wholesale trade and agriculture are classified as hierarchical transmission sectors, together with construction, retail trade, financial services and basic metals. Selective transmission sectors include food and beverages, metal products, land transport, other business support activities and real estate

12 The intermediation capacity is measured by the betweenness centrality indicator. This depicts how well situated a node is in terms of the path that it lies on. In general, the concept of distance in network analysis is related to the number of steps needed for a given node "to reach" another node in the network. The shortest path between node $i$ and node $j$ is called geodesic distance. Betweenness centrality assigns highest score to nodes that lie on a larger proportion of shortest paths linking pairs of other nodes. Betweenness centrality is a useful measure in the cases when a node is important as an intermediary, i.e. in a communication network. A node is crucial in the transmission of information if informative flows are disrupted or must make longer path if that node stops passing information or if it disappear from the network. 


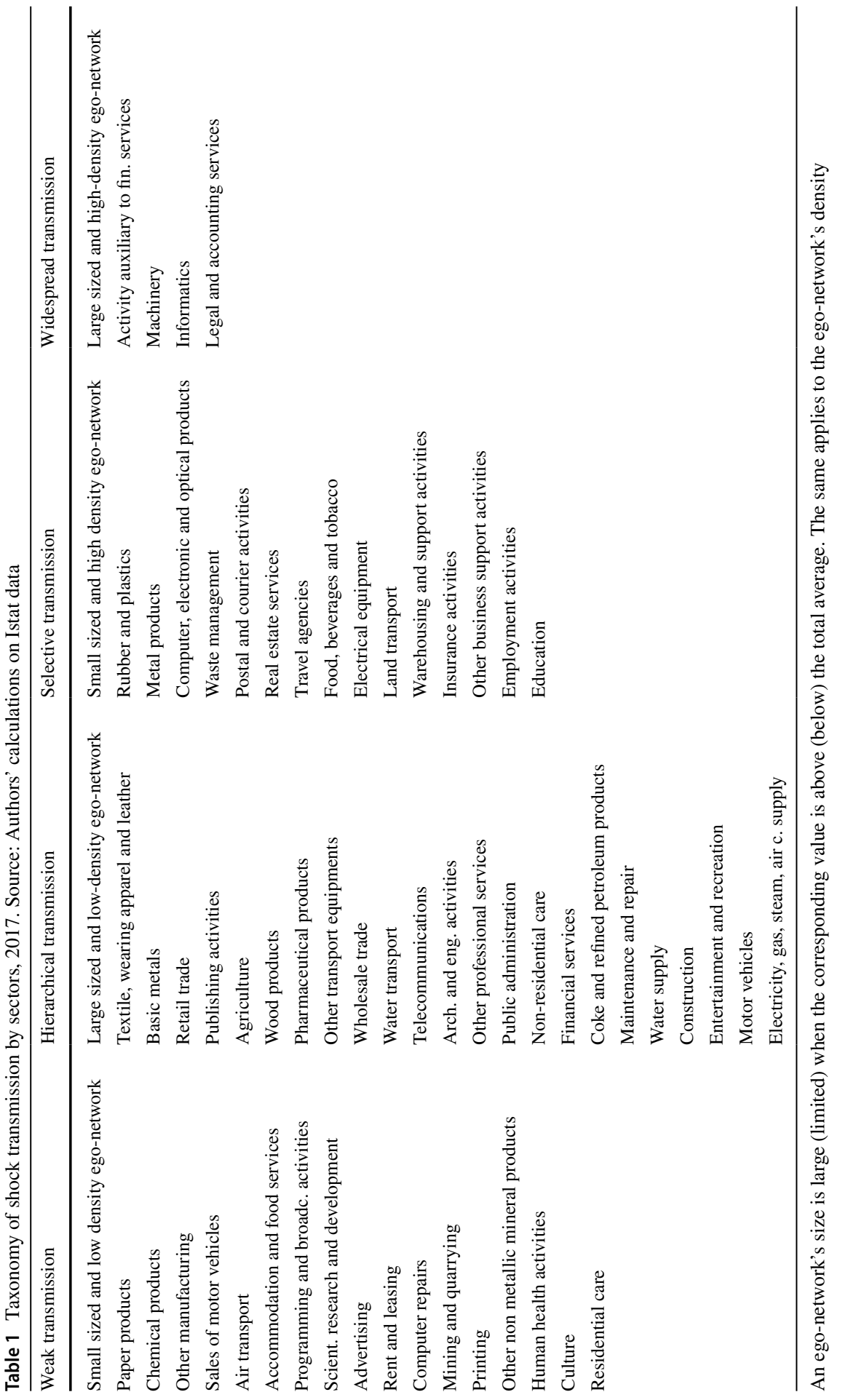


services. The widespread transmission group is particularly small: out of four sectors included, however, two (machinery and legal and accounting services) are among the most central in domestic relationships. Finally, accommodation and food services are included in the group of weak transmission sectors.

Therefore, the Italian economic sectors are mostly characterized by hierarchical shock transmission: this category includes the majority of firms (over 55\%) which also account for the largest share in terms of value added, employment, exports, imports and output (Table 2). These industries, however, does not have on average the most intense connections with foreign markets: their degree of trade openness (56.8\%) is high but considerably lower than that of sectors included in the widespread transmission group $(82.3 \%)$, and substantially similar to that of selective transmission sectors.

It is worth noticing that the highest average productivity characterizes the widespread transmission sectors. This may be a point of concern for the Italian economy, because their lack of centrality in domestic relationships can weaken any spillover of competitiveness.

In fact, the speed and the scale of the transmission depend also on the positioning (central or peripheral) of sectors within the Italian trade network. In this respect, Fig. 6 gives a representation of the cross-sectoral relationships structure through the overall eigenvector centrality. Here, the size of nodes represents the relevance of sectors in terms of value added, while colors indicate their belonging to the four classes of the taxonomy. The thickness of the arcs reflects the value of transactions underlying the linkages.

On the one hand, all four widespread transmission sectors (in red) are placed in the intermediate "crown" of the trade network. The central part, on the other hand, is characterized by the presence of both selective transmission (in orange; in particular Food beverages and tobacco, land transport, warehousing and support activities, real estate) and hierarchical transmission sectors (in grey; in particular wholesale trade, agriculture, motor vehicles, construction). Weak transmission sectors (in black) are in peripheral position, with the exception of accommodation and food services. Moreover, all the sectors contributing the most to the overall value added tend to position themselves at the center of the network, with the exception of healthcare, social welfare, education and public administration.

On the one hand, all four widespread transmission sectors (in red) are placed in the intermediate "crown" of the trade network. The central part, on the other hand, is characterized by the presence of both selective transmission (in orange; in particular food beverages and tobacco, land transport, warehousing and support activities, real estate) and hierarchical transmission sectors (in grey; in particular wholesale trade, agriculture, motor vehicles, construction). Weak transmission sectors (in black) are in peripheral position, with the exception of accommodation and food services. Moreover, all the sectors contributing the most to the overall value added tend to position themselves at the center of the network, with the exception of healthcare, social welfare, education and public administration.

A further noteworthy aspect concerns how the four groups interact with each other, as well as the extent to which this interaction affects the transmission of shocks within the economy. In this respect, we consider both the "relevance" and the 
"density" of the interactions between groups. The "relevance" is given by the ratio between the number of bilateral relationships linking sectors of different groups and the total number of active relationships in the economic system (Table 3A). The "density" is given by the ratio between the number of bilateral relationships linking sectors of different groups and the total number of potential links that could be activated by the industries belonging to those two groups (Table 3B).

As for the relevance, the relative majority of these relationships (16\% of the total) occur among hierarchical transmission sectors, while transactions from hierarchical transmission to weak transmission sectors account for $12 \%$ of the total. The reverse flow also appears to be of some importance (10.4\%). For $10 \%$ of total transactions, the propagation of a possible shock is fast (outgoing flows from hierarchical sectors to selective ones), for $10.9 \%$ it is wide (outgoing flows from selective sectors to hierarchical ones). Finally, the small number of widespread transmission sectors implies a low relevance of the incoming and outgoing transactions activated with sectors belonging to the other three categories of the taxonomy.

Nevertheless, in terms of density, the widespread transmission sectors have a high propensity to interact with the sectors of the other groups (in particular the hierarchical transmission ones), both outward (with a density of 37\%) and inward (30\%). A lower but still relevant density characterizes the relationships between selective and hierarchical sectors.

The centrality (and the economic relevance) of the domestic bilateral linkages of a number of hierarchical and selective transmission sectors places them in a privileged position to propagate shocks of internal origin. In case of shocks from abroad, this capacity directly depends on the openness of the given industry to international markets. Comparing the evidence found in Sects. 4 and 5, however, only motor vehicles (hierarchical transmission group), machinery (widespread) and metal products (selective) show both a high openness to international markets and a central position within the Italian business system.

Furthermore, this aspect can have important consequences in terms of technological progress, as a higher centrality in the trade relationships with other countries' most productive sectors makes many Italian medium-high technology manufacturing industries more reactive to stimuli coming from abroad. However, their lower centrality within the domestic network limits their ability to transmit these impulses to the rest of the business system. Conversely, the technological upgrading of lowmedium technology industries, which are more connected with domestic sectors, and therefore with higher transmission capacity, may be limited by their close links with the relatively less productive foreign sectors (Istat, 2019).

Moreover, since hierarchical transmission sectors intermediate exchanges within their ego-networks, the propagation of shocks is strongly affected by their own characteristics, for example in terms of technological content, input requirements, productivity. At the same time, widespread transmission sectors (that transmit the stimuli faster and to a wider extent) tend to be less central in the trade network and, with the exception of machinery, they are also less sensitive to foreign shocks. Therefore, the Italian business system appears to generally suffer from a structural mismatch that weakens its ability to efficiently and quickly intercept potential positive shocks 


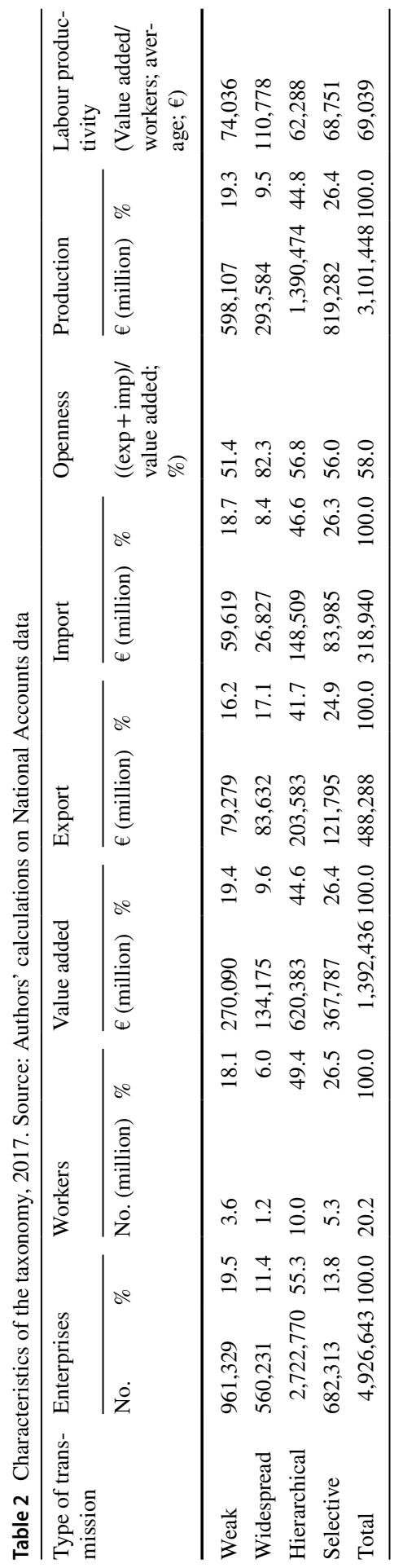




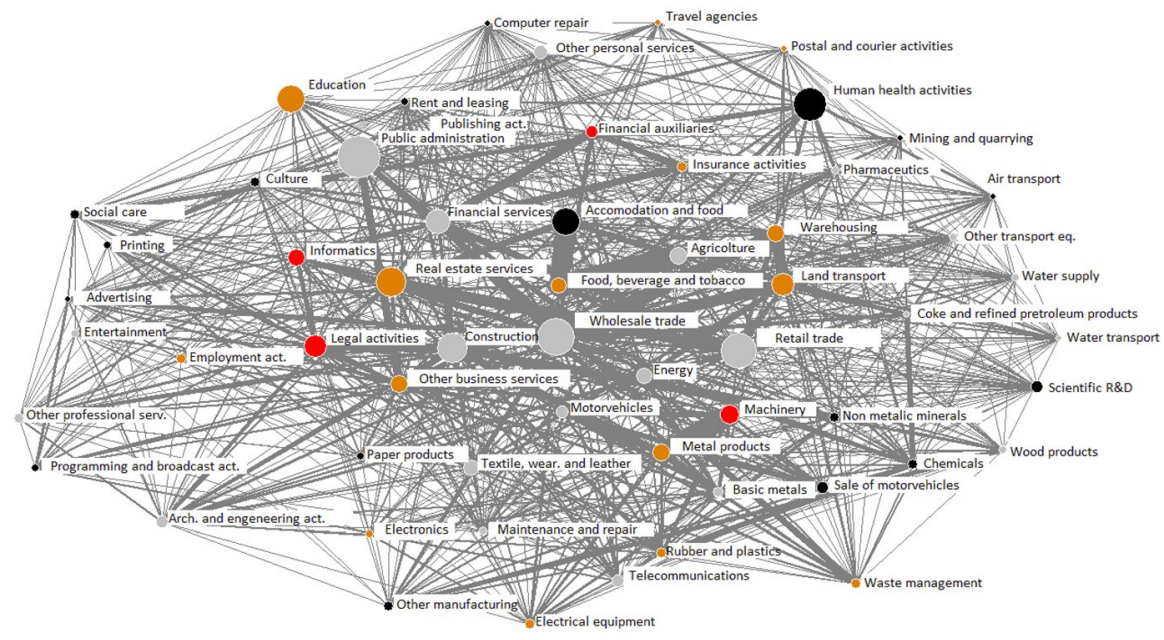

Note: Red sectors: widespread transmission; Orange: selective transmission; Grey: hierarchical transmission; Black: weak transmission. In this graph all the bilateral transactions whose value exceeds $3 \%$ of total incoming or outgoing flows are reported for each node. Thickness of arcs reflects the weight of the relationships in terms of the value of transactions.

Fig. 6 Graph of inter-sectoral relationships, 2017. Red sectors: widespread transmission; Orange: selective transmission; Grey: hierarchical transmission; Black: weak transmission. In this graph all the bilateral transactions whose value exceeds $3 \%$ of total incoming or outgoing flows are reported for each node. Thickness of arcs reflects the weight of the relationships in terms of the value of transactions. Source: Authors' calculations on Istat data

of foreign demand (thus benefiting from business cycle of growing countries) or to benefit from technology or productivity spillovers.

\section{Conclusions}

This work studies transmission mechanisms of domestic and foreign shocks within the Italian business system through the analysis of the trade network, both at international (i.e., the links between Italian industries and foreign countries) and domestic level (i.e., the inter-sectoral relationships among Italian industries). To this aim, we propose a new taxonomy of sectors based on the extent to, and speed at which, they transmit shocks within the business system.

Our findings point out a mismatch between industries having a central position in terms of transmission of foreign shocks and those having a central role for their domestic propagation. Most manufacturing sectors are more open to foreign markets and, therefore, should be in principle the most relevant in the domestic transmission of shocks from abroad. However, a substantial part of them tends to play more a central role in international relationships than in domestic ones (textile, wearing apparel and leather, pharmaceutics products, not metallic minerals, other transport equipment). Only a small group of sectors (motor vehicles, machinery, metal products) 


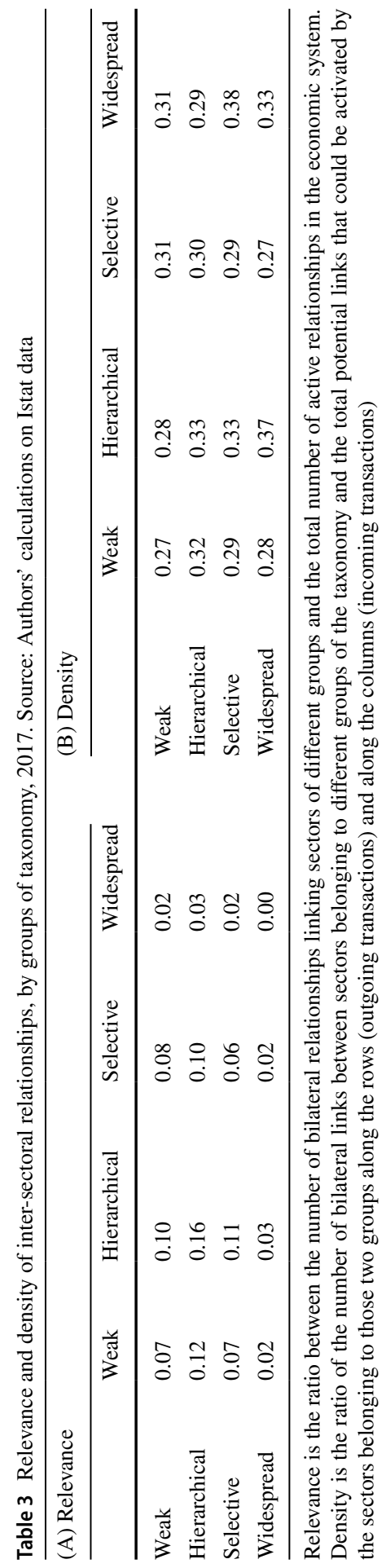


has both a high exposure to international markets and a central position within the Italian trade network. This makes more difficult, for Italy, to benefit from positive foreign spillovers and move on to more dynamic growth paths.

The speed and extent of shocks transmission are also relevant. In this respect, the proposed taxonomy shows that at the center of the domestic network mainly lie sectors with a wide but slow transmission capacity (hierarchical transmission sectors: wholesale trade, agriculture, motor vehicles, construction), and sectors with a narrow but fast transmission capacity (selective transmission sectors: food and beverages, land transport, warehousing and support activities, real estate). Furthermore, the interactions between the sectors of these two groups account for a large share of total transactions within the Italian business system, both effective (i.e., already activated) and potential (i.e., which may be activated). On the contrary, the small number of widespread transmission sectors, their relatively more decentralized position within the network and the reduced openness to international markets (with the exception of machinery) limit the possibility of spreading impulses to both an extensive and a rapid way.

To sum up, the compresence of both the aforementioned mismatch in trade networks and the distribution of sectors among the four classes of the taxonomy tends to limit the transmission of foreign shocks within the Italian economy. On the one hand, this compromises the possibility of benefiting from positive shocks in foreign demand; on the other hand, it could provide a possible "shelter" in the case of negative impulses deriving from international business cycle downturns.

\section{Declarations}

Conflict of interest On behalf of all authors, the corresponding author states that there is no conflict of interest.

\section{References}

Acemoglu, D., Ozdaglar A., \& Tahbaz-Salehi, A. (2015). Networks, shocks, and systemic risk. In Y. Bramoull'e, A. Galeotti, \& B. Rogers (Eds.), The oxford handbook on the economics of networks. Oxford University Press. https://doi.org/10.3386/w20931

Acemoglu, D., Akcigit, U., \& Kerr, W. (2016a). Networks and the macroeconomy: An empirical exploration. Nber Macroeconomics Annual, 30(1), 273-335. https://doi.org/10.1086/685961

Acemoglu, D., Akcigit, U., \& Kerr, W. R. (2016b). Innovation network. Proceedings of the National Academy of Sciences, 113(41), 11483-11488. https://doi.org/10.1073/pnas.1613559113

Acemoglu, D., Carvalho, V. M., Ozdaglar, A., \& Tahbaz-Salehi, A. (2012). The network origins of aggregate fluctuations. Econometrica, 80, 1977-2016. https://doi.org/10.3982/ECTA9623

Alatriste Contreras, M. G., \& Fagiolo, G. (2014). Propagation of economic shocks in input-output networks: A cross-country analysis. Physical Review E, 90(6), 062812. https://doi.org/10.1103/PhysR evE.90.062812

Baldwin, R. (2013). Global Supply Chains: Why they emerge, why they matter, and where they are going. In D. Kelms \& P. Low (Eds.), Global value chains in a changing world, pp. 13-59. WTO Publications, Geneva. https://doi.org/10.30875/0b68ab34-en

Baqaee, D. R., \& Farhi, E. (2019). The macroeconomic impact of microeconomic shocks: Beyond Hulten's theorem. Econometrica, 87(4), 1155-1203. https://doi.org/10.3982/ECTA15202 
Barba Navaretti, G., Bugamelli, M., Schivardi, F., Altomonte, C., \& Horgos, D. (2011). The global operations of European firms. The second EFIGE policy report. Bruegel Blueprint 12, July 2011.

Bernanke, B. S., Gertler, M., \& Gilchrist, S. (1999). The financial accelerator in a quantitative business cycle framework. Handbook of Macroeconomics, 1, 1341-1393. https://doi.org/10.1016/S15740048(99)10034-X

Bonacich, P. (1972). Factoring and weighting approaches to status scores and clique identification. Journal of Mathematical Sociology, 2(1), 113-120. https://doi.org/10.1080/0022250X.1972.9989806

Borgatti, S. P. (2005). Centrality and network flow. Social Networks, 27, 55-71. https://doi.org/10.1016/j. socnet.2004.11.008

Borgatti, S. P., Everett, M. G., \& Freeman, L. C. (2002). Ucinet for Windows: Software for social network analysis (p. 6). Harvard, MA: Analytic technologies.

Borgatti, S. P., Everett, M. G., \& Johnson, J. C. (2018). Analyzing social networks. Sage.

Carvalho, V., \& Gabaix, X. (2013). The great diversification and its undoing. American Economic Review, 103(5), 1697-1727. https://doi.org/10.1257/aer.103.5.1697

Cerina, F., Zhu, Z., Chessa, A., \& Riccaboni, M. (2015). World input-output network. PLoS ONE, 10(7), e0134025. https://doi.org/10.1371/journal.pone.0134025

Conley, T. G., \& Dupor, B. (2003). A spatial analysis of sectoral complementarity. Journal of Political Economy, 111(2), 311-352. https://doi.org/10.1086/367681

Costa, S., Sallusti, F., Vicarelli, C., \& Zurlo, D. (2021). From micro to macro: Micro-foundations of the italian business cycle co-movements during the crises. Italian Economic Journal. https://doi.org/10. 1007/s40797-021-00163-2

Criscuolo, C., \& Timmis, J. (2018). GVCs and centrality: Mapping key hubs, spokes and the periphery. https://doi.org/10.1787/d4a9bd6f-en

De Benedictis, L., Nenci, S., Santoni, G., Tajoli, L., \& Vicarelli, C. (2014). Network analysis of world trade using the BACI-CEPII dataset. Global Economy Journal, 14(3-4), 287-343. https://doi.org/ 10.1515/gej-2014-0032

di Giovanni, J., \& Levchenko, A. A. (2012). Country size, international trade, and aggregate fluctuations in granular economies. Journal of Political Economy, 120(6), 1083-1132. https://doi.org/10.1086/ 669161

di Giovanni, J., Levchenko, A. A., \& Méjean, I. (2014). Firms, destinations, and aggregate fluctuations. Econometrica, 82, 1303-1340. https://doi.org/10.3982/ECTA11041

di Giovanni, J., Levchenko, A. A., \& Méjean I. (2018). The micro origins of international business-cycle comovement. American Economic Review, 108(1), 82-108.

Dupor, B. (1999). Aggregation and irrelevance in multi-sector models. Journal of Monetary Economics, 43(2), 391-409. https://doi.org/10.1016/S0304-3932(98)00057-9

Fagiolo, G., Reyes, J., \& Schiavo, S. (2010). The evolution of the world trade web: A weighted-network analysis. Journal of Evolutionary Economics, 20(4), 479-514.

Foerster, A. T., Sarte, P. D. G., \& Watson, M. W. (2011). Sectoral versus aggregate shocks: A structural factor analysis of industrial production. Journal of Political Economy, 119(1), 1-38. https://doi.org/ 10.1086/659311

Frankel, J. A., \& Rose, A. K. (1998). The endogenity of the optimum currency area criteria. The Economic Journal, 108(449), 1009-1025. https://doi.org/10.1111/1468-0297.00327

Friedman, M., \& Schwartz, A. J. (2008). A monetary history of the United States, 1867-1960 (Vol. 14). Princeton University Press.

Gabaix, X. (2011). The granular origins of aggregate fluctuations. Econometrica, 79(3), 733-772. https:// doi.org/10.3982/ECTA8769

Giammetti, R., Russo, A., \& Gallegati, M. (2020). Key sectors in input-output production networks: An application to Brexit. The World Economy, 43(4), 840-870. https://doi.org/10.1111/twec.12920

Horvath, M. (1998). Cyclicality and sectoral linkages: Aggregate fluctuations from independent sectoral shocks. Review of Economic Dynamics, 1(4), 781-808. https://doi.org/10.1006/redy.1998.0028

Horvath, M. (2000). Sectoral shocks and aggregate fluctuations. Journal of Monetary Economics, 45(1), 69-106. https://doi.org/10.1016/S0304-3932(99)00044-6

Istat. (2019). Rapporto sulla competitività dei settori produttivi. Marzo, Roma, available at https://www. istat.it/it/archivio/228641 (in Italian).

Istat. (2020a). Rapporto sulla competitività dei settori produttivi. Marzo, Roma, available at https://www. istat.it/it/archivio/240112 (in Italian).

Istat. (2020b). Rapporto annuale. Luglio, Roma, available at https://www.istat.it/it/archivio/2444848 (in Italian). 
Jackson, M. O. (2010). Social and economic networks. Princeton University Press.https://doi.org/10. $1515 / 9781400833993$

Jones, C. I. (2012). Misallocation, economic growth, and input-output economics. In M. Arellano, D. Acemoglu, \& E. Dekel (Eds.), Advances in economics and econometrics, Cambridge University Press, New York. https://doi.org/10.3386/w16742

Krugman, P., Cooper, R. N., \& Srinivasan, T. N. (1995). Growing world trade: Causes and consequences. Brookings Papers on Economic Activity, 1995(1), 327-377. https://doi.org/10.2307/2534577

Kydland, F. E., \& Prescott, E. C. (1982). Time to build and aggregate fluctuations. Econometrica: Journal of the Econometric Society. https://doi.org/10.2307/1913386

Long, J. B., Jr., \& Plosser, C. I. (1983). Real business cycles. Journal of Political Economy, 91(1), 39-69. https://doi.org/10.1086/261128

Mayer, T., \& Ottaviano, G. I. (2007). The happy few: The internationalisation of European firms. New facts based on firm-level evidence. Bruegel blueprint series, Volume 3, November 2007.

Minoiu, C. \& Reyes J. A. (2013). A network analysis of global banking: 1978-2010. Journal of Financial Stability, 9(2), 168-184. https://doi.org/10.1016/j.jfs.2013.03.001

Shea, J. (2002). Complementarities and comovements. Journal of Money, Credit and Banking, 34(2), $412-433$.

Stock, J. H., \& Watson, M. W. (1999). Business cycle fluctuations in US macroeconomic time series. Handbook of Macroeconomics, 1, 3-64. https://doi.org/10.1016/S1574-0048(99)01004-6

Timmer, M. P., Dietzenbacher, E., Los, B., Stehrer, R., \& De Vries, G. J. (2015). An illustrated user guide to the world input-output database: The case of global automotive production. Review of International Economics, 23(3), 575-605. https://doi.org/10.1111/roie.12178

Tsekeris, T. (2017). Global value chains: Building blocks and network dynamics. Physica a: Statistical Mechanics and Its Applications, 488, 187-204. https://doi.org/10.1016/j.physa.2017.06.019

Wasserman, S., \& Faust, K. (1994). Social network analysis: Methods and applications.

World Bank Group, IDE-Jetro, OECD, UIBE, WTO. (2017). Global value chains development report 2017, available at https://www.wto.org/english/res_e/booksp_e/gvcs_report_2017.pdf

Xiao, H., Sun, T., Meng, B., \& Cheng, L. (2017). Complex network analysis for characterizing global value chains in equipment manufacturing. PLOS ONE, 12(1), e0169549. https://doi.org/10.1371/ journal.pone.0169549

Xing, L., Ye, Q., \& Guan, J. (2016). Spreading effect in industrial complex network based on revised structural holes theory. PLOS ONE, 11(5), e0156270. https://doi.org/10.1371/journal.pone.0156270

Publisher's Note Springer Nature remains neutral with regard to jurisdictional claims in published maps and institutional affiliations. 